\title{
Relation between Antibacterial Activity against Food Transmitted Pathogens and Total Phenolic Compounds in Grape Pomace Extracts from Cabernet Sauvignon and Syrah Varieties
}

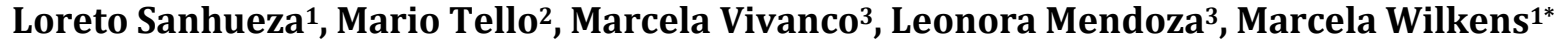 \\ ${ }^{1}$ Laboratorio de Microbiología Básica y Aplicada, Facultad de Química y Biología, Universidad de Santiago de \\ Chile, Santiago, Chile \\ ${ }^{2}$ Laboratorio de Metagenómica Bacteriana, Facultad de Química y Biología, Universidad de Santiago de Chile, \\ Santiago, Chile \\ ${ }^{3}$ Laboratorio de Micología, Facultad de Química y Biología, Facultad de Química y Biología, Universidad de \\ Santiago de Chile, Santiago, Chile \\ Email: ${ }^{*}$ marcela.wilkens@usach.cl
}

Received 26 February 2014; revised 26 March 2014; accepted 2 April 2014

Copyright @ 2014 by authors and Scientific Research Publishing Inc.

This work is licensed under the Creative Commons Attribution International License (CC BY).

http://creativecommons.org/licenses/by/4.0/

(c) (j) Open Access

\section{Abstract}

Grape pomace is the main by-product of wine production that concentrates bioactive metabolites of polyphenolic nature with antibacterial activity. Since grape pomace composition varied depending on grape variety, climate, vineyard location, and winemaking technology, it is important to study the composition and antibacterial activity of each variety separately. In this study, antibacterial activity against different food pathogens was evaluated and its relation with polyphenols content was determined. Grape pomace from Cabernet Sauvignon and Syrah varieties was extracted with methanol/HCl 1\% (v/v), followed by sequential extractions with hexane, chloroform and ethyl acetate. Ethyl acetate fraction had the highest antibacterial activity determined through the microdilution method, reaching over $90 \%$ of inhibition at $500 \mu \mathrm{g} \cdot \mathrm{ml}^{-1}$ with the exception of Salmonella Typhi (70\% of inhibition). Staphylococcus aureus and Escherichia coli were the most susceptible strains, exceeding $50 \%$ of inhibition at $62.5 \mu \mathrm{g} \cdot \mathrm{ml}^{-1}$. Ethyl acetate fraction contains the highest phenolic concentration in both Cabernet Sauvignon (132.2 mg of GAE $\mathrm{g}^{-1}$ ) and Syrah (102.6 mg of GAE $\mathrm{g}^{-1}$ ) pomace, as determined by the Folin-Ciocalteau method. Antibacterial activity present in grape pomace extracts is in direct relation to the polar phenolic content, in particular

${ }^{*}$ Corresponding author.

How to cite this paper: Sanhueza, L., et al. (2014) Relation between Antibacterial Activity against Food Transmitted Pathogens and Total Phenolic Compounds in Grape Pomace Extracts from Cabernet Sauvignon and Syrah Varieties. Advances in Microbiology, 4, 225-232. http://dx.doi.org/10.4236/aim.2014.45029 


\title{
that from Cabernet Sauvignon.
}

\author{
Keywords
}

Antibacterial Activity, Grape Pomace Extract, Ethyl Acetate Fraction, Total Phenolic Content

\section{Introduction}

Contamination of food by multiresistant infectious bacteria has become a serious problem, because they limit the treatment and effectiveness of the antibiotics currently in clinical use. This has stimulated the search for compounds with antibacterial activity from natural sources. Fruit peel and seeds are rich in bioactive substances such as phenolic acids and flavonoids [1]-[3] which are known to possess antibacterial activity [4]-[6]. Grapes (Vitis vinifera) are one of the world's largest fruit crops, with an annual world production of 70 million tons in 2010 (http://faostat.fao.org). It is estimated that more than $80 \%$ of total grape production is used in winemaking [7]. The main organic waste produced in wine industries is grape pomace [3], representing $13 \%$ to $25 \%$ of the total weight of processed fruit [1]-[8]. This waste is produced after pressing the crushed grapes in white wine processing or after fermentation in red wine production. Its main components are fragmented skin, broken cells, pulp remains, stalks, and seeds [9]-[11] and it contains high amount of phenolic compounds due to their poor extraction during the winemaking process [12]. Anthocyanins, catechins, flavonol glycosides, phenolic acids, alcohols and stilbenes have been identified among the compounds present in grape pomace [8] [13]-[15].

Antibacterial activity has also been determined in extracts obtained from whole fruits [16], seeds [17]-[20], pomaces [17]-[21] and skins [18]. Organic extracts from seeds showed bacteriostatic activity against anaerobic bacteria responsible for periodontal diseases [19], and they were also able to inhibit hydrofolate reductase activity in Staphylococcus aureus [20]. Thimothe et al. (2007) showed inhibition of glucosyltransferases B and C in Streptococcus mutans by all the grape extracts studied. Furthermore, it has been determined that seeds and pomace extracts obtained with different solvents have distinct polyphenolic content [21] [22]. As grape pomace is a food waste containing antibacterial activity, it represents a huge potential for controlling pathogens transmitted through food, however their ability to control these pathogens has not been explored previously. Since grape pomace composition varies depending on grape variety, climate, vineyard location, and winemaking technology [8]-[10], it is important to investigate the composition and antibacterial activity of each variety separately and thus explore more deeply the biotechnological applications of this residue of the wine industry. In this study, the presence of antibacterial activity against food pathogens was evaluated (Escherichia coli, Salmonella Typhi, S. aureus, and Listeria monocytogenes) in organic extracts obtained from two varieties of grape pomace. We also evaluated the relationship between this activity and the total content of phenolic compounds.

\section{Experimental}

\subsection{Grape Pomace Extracts}

The grape pomace samples were obtained after the fermentation process from the 2009 harvest season of the Cabernet Sauvignon and Syrah varieties of the Miguel Torres vineyard (Curicó, Chile). The pomace was kept at $-20^{\circ} \mathrm{C}$ before use. Each pomace sample (450 g) was ground and extracted with $1 \mathrm{~L}$ of methanol/HCl $1 \%(\mathrm{v} / \mathrm{v})$ for $4 \mathrm{~h}$ at $4^{\circ} \mathrm{C}$ with constant agitation $(100 \mathrm{rpm})$, concentrated in a rotary evaporator at $50^{\circ} \mathrm{C}$, and subjected to sequential liquid-liquid extraction with hexane, chloroform and ethyl acetate [15]. Finally, the fractions were concentrated to dryness and kept at $-20^{\circ} \mathrm{C}$. For the experiments described below, each extract was dissolved in methanol.

\subsection{Determination of Total Phenolic Content}

The total phenolic content (TPC) determination in each pomace extract was performed using the Folin-Ciocalteau method [23]. The Folin-Ciocalteau reagent used in these experiments was Sigma-Aldrich and the absorbance was measured at $765 \mathrm{~nm}$ on a Shimadzu model UV-VIS-1240 spectrometer. The estimation of phenolic compounds in the extract was calculated from a calibration curve obtained with gallic acid equivalents. TPC was 
expressed in milligrams of gallic acid per gram of extract (mg GAE $\mathrm{g}^{-1}$ extract). All samples were analyzed in triplicate.

\subsection{Bacterial Strains and Culture Media}

Two Gram negative bacteria, E. coli ATCC 25922 and S. Typhi STH-2370, and the Gram positive bacteria $S$. aureus ATCC 6538, were grown in Mueller-Hinton media (MH-B, Merck). Gram positive L. monocytogenes ATCC 15313 was grown in a 1:1 mixture of Brain Heart Infusion (BHI, Merck) and Tryptic Soy Broth (TSB, Becton Dickinson). All bacterial cultures were maintained in solid agar media at $4^{\circ} \mathrm{C}$, and for each experiment a single colony was inoculated in the corresponding liquid medium and incubated at $37^{\circ} \mathrm{C}$ for $18 \mathrm{~h}$.

\subsection{Antibacterial Activity Determination}

The antibacterial activity was determined in 96-well microdilution plates following the Clinical Laboratory Standards Institute (CLSI, www.clsi.org) recommendations. Grape pomace extracts dissolved in methanol at different final concentrations were assayed $\left(62.5,125,250\right.$ and $\left.500 \mu \mathrm{g} \cdot \mathrm{ml}^{-1}\right)$. The plates were incubated at $37^{\circ} \mathrm{C}$ for $18 \mathrm{~h}$ and the absorbance at $600 \mathrm{~nm}$ was determined in an Elisa reader (Thermos Labsystems Multiskan FC Model). The inhibition equation was used to calculate the inhibition percentage of each extract, where, $\mathrm{TA}_{600}$ is the absorbance of the sample (microdilution assays with different fractions of grape pomace extract), $\mathrm{EA}_{600}$ is absorbance control and $\mathrm{SA}_{600}$ is growth control.

$$
(\%)=\left(100-\left(\left(100 \times\left(\mathrm{TA}_{600}-\mathrm{EA}_{600}\right)\right)\left(\mathrm{SA}_{600}\right)^{-1}\right)\right)
$$

\section{Results}

\subsection{Total Phenolic Content}

Table 1 summarizes the TPC of the different fractions of grape pomace extracts obtained from the Cabernet Sauvignon and Syrah grape varieties. The TPC varied depending on the polarity of solvents used for the fractionation (hexane, chloroform and ethyl acetate), showing with the most non polar solvent (hexane) the lowest value among the fractions of both grape varieties. By other hand, highest TPCs were obtained with the more polar solvent, reaching the ethyl acetate fraction 132.229 and $102.592 \mathrm{mg} \mathrm{GAE} \mathrm{g}^{-1}$ extract for Cabernet Sauvignon and Syrah, respectively. These results show that TPC concentration in the different fractions depends directly on the solvents polarity.

Moreover, the total phenolic content in grape pomace extract is also dependent on the grape variety, as shown in Table 1. The fractions obtained with hexane, chloroform and ethyl acetate from the Cabernet Sauvignon variety showed significant higher $(\mathrm{P}<0.001)$ TPC concentrations compared to the Syrah variety.

\subsection{Antibacterial Activity of Grape Pomace Extracts}

All fractions of grape pomace extracts showed antibacterial activity against all the tested strains of Gram positive and Gram negative bacteria, indicating that they have a broad spectrum action.

In general, $S$. aureus and $E$. coli were the most sensitive strains to the antibacterial activity of the compounds present in grape pomace extract, as shown in Figure 1 and Figure 2. For all the bacteria tested, hexane extracts were less active, with $80 \%$ maximum inhibition against $S$. aureus and $L$. monocytogenes at $500 \mu \mathrm{g} \cdot \mathrm{ml}^{-1}$, while

\begin{tabular}{ccc|} 
Table 1. Total phenolics in grape pomace fractions. \\
\hline Fraction & \multicolumn{2}{c|}{ Total phenolic content $\left(\mathrm{mg} \mathrm{GAE} \mathrm{g}^{-1}\right.$ extract) } \\
\cline { 2 - 3 } & Cabernet Sauvignon & Syrah \\
\hline Hexane & $12.577 \pm 1.66$ & $6.989 \pm 0.4^{*}$ \\
Chloroform & $68.592 \pm 4.4$ & $42.032 \pm 3.3^{*}$ \\
Ethyl acetate & $132.229 \pm 4.8$ & $102.592 \pm 3.7^{*}$ \\
\hline
\end{tabular}

${ }^{*}$ t-test $\mathrm{P}<0.001$. 


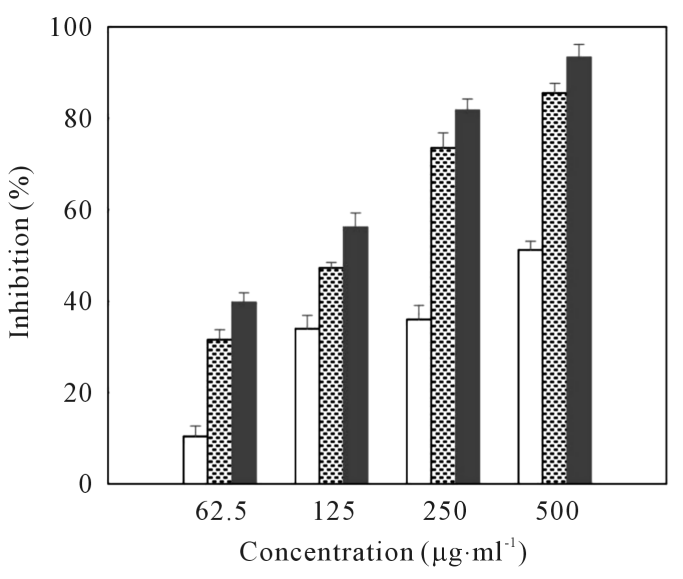

(a)

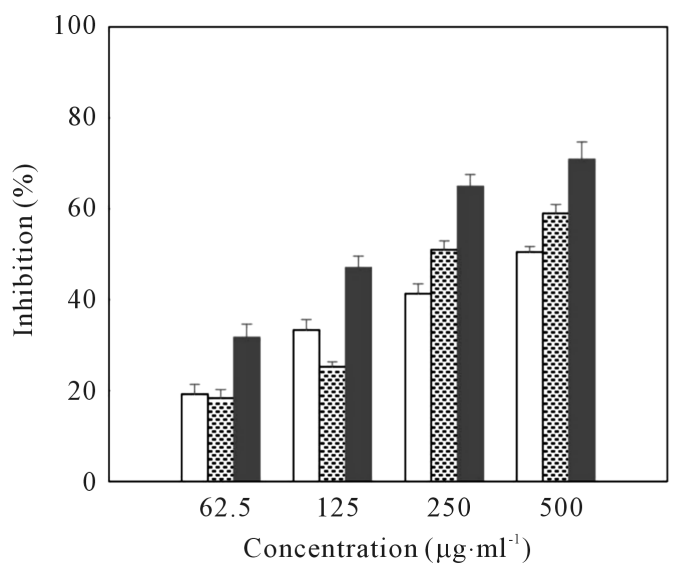

(c)

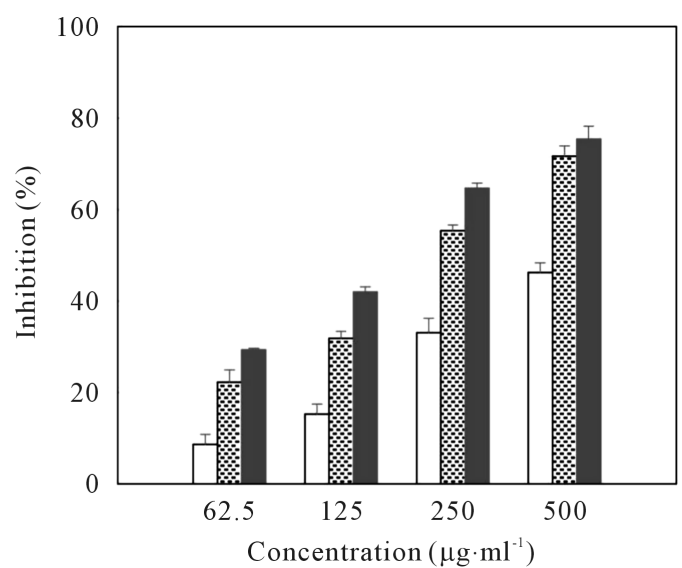

(b)

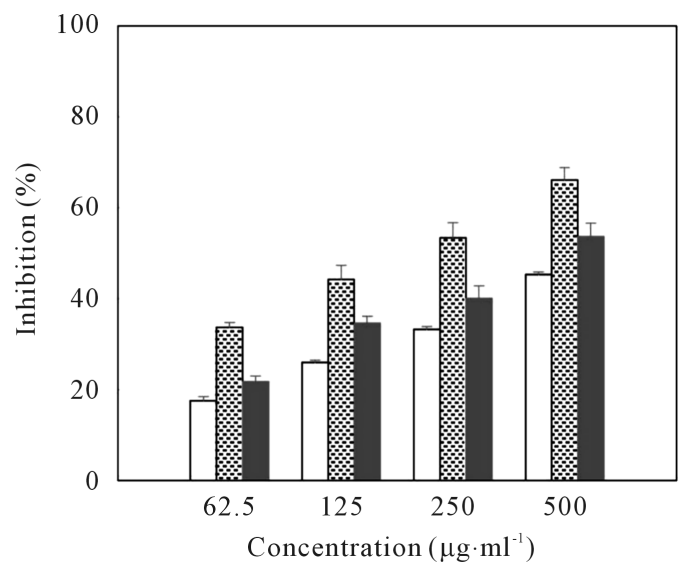

(d)

\begin{abstract}
Figure 1. Antibacterial activity of grape pomace extracts against Gram positive bacteria. The figure shows the effect of grape pomace extracts obtained using hexane (white bars), chloroform (hatched bars) and ethyl acetate (gray bars) on bacterial growth of S. aureus (a) and (b) and L. monocytogenes (c) and (d). Extracts from Cabernet Sauvignon (a) and (c) and Syrah (b) and (d) varieties were analyzed.
\end{abstract}

extracts from the Cabernet Sauvignon variety fractionated with chloroform and ethyl acetate showed greater antibacterial activity on all tested bacteria. The growth inhibition of $S$. aureus reached $90 \%$ and $98 \%$ for the chloroform and ethyl acetate fractions, respectively, at the highest concentration used. Moreover, at the lowest concentration, $62.5 \mu \mathrm{g} \cdot \mathrm{ml}^{-1}$, inhibition was $50 \%$ and $60 \%$, respectively. Although $L$. monocytogenes was less susceptible than $S$. aureus to the extracts fractionated with chloroform and ethyl acetate from both grape varieties, inhibition values were close to $90 \%$. Furthermore, extracts from the Syrah variety showed less activity than Cabernet Sauvignon extracts, with inhibition against S. aureus and L. monocytogenes not exceeding $90 \%$ and $45 \%$ at concentrations of 500 and $62.5 \mu \mathrm{g} \cdot \mathrm{ml}^{-1}$, respectively.

On the other hand, the Gram negative bacteria E. coli and S. Typhi showed higher growth inhibition with Cabernet Sauvignon extracts (Figure 2). Again, all fractions of the Syrah variety extracts showed lower antibacterial activity compared to Cabernet Sauvignon. Of the two Gram negative bacteria tested, both E. coli and $S$. Typhi showed the same trend at all the concentrations used, but $S$. Typhi was less susceptible, reaching $70 \%$ maximum inhibition at a concentration of $500 \mu \mathrm{g} \cdot \mathrm{ml}^{-1}$.

\title{
4. Discussion
}

\subsection{Total Phenolic Content}

In this work, the concentration of polyphenolic compounds found in the different fractions are in agreement with 


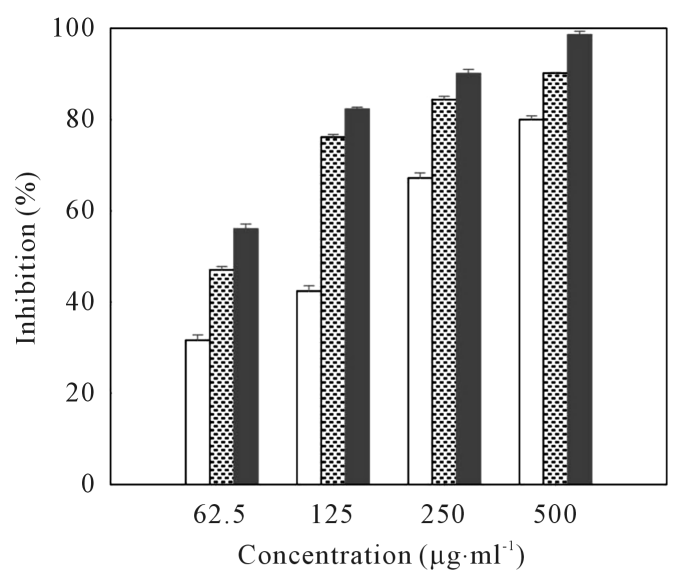

(a)

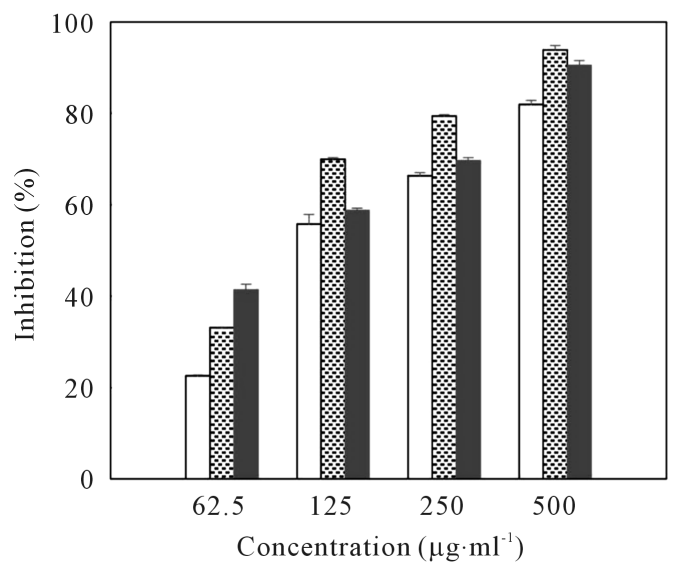

(c)

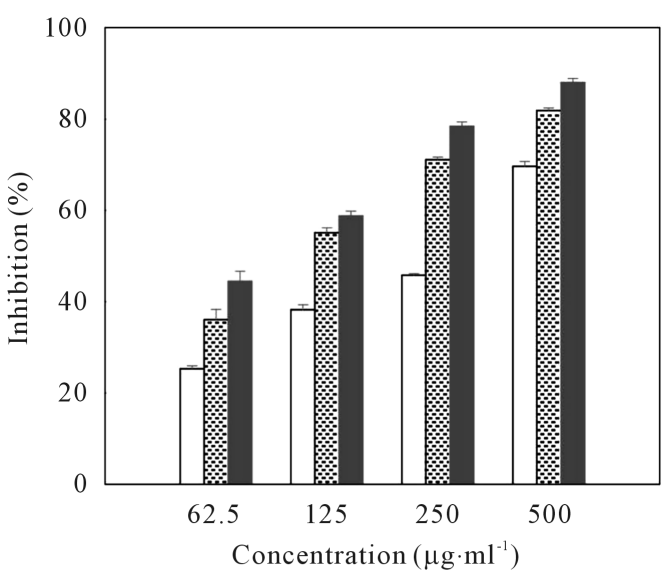

(b)

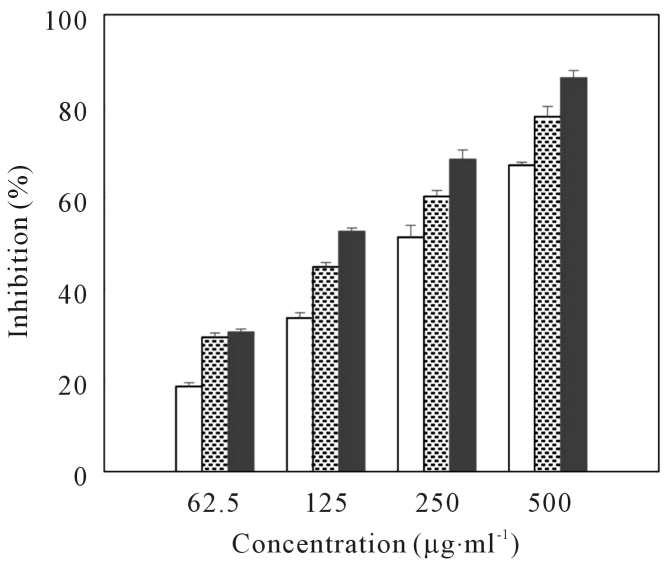

(d)

Figure 2. Antibacterial activity of grape pomace extracts against Gram negative bacteria. The figure shows the effect of grape pomace extracts obtained using hexane (white bars), chloroform (hatched bars) and ethyl acetate (gray bars) on bacterial growth of E. coli (a) and (b) and S. Typhi (c) and (d). Extracts from Cabernet Sauvignon (a) and (c) and Syrah (b) and (d) varieties were analyzed.

results of Jayaprakasha et al. (2003), who reported that an acetone:water:acetic acid (90:9.5:0.5) solvent mixture is more efficient than one of methanol:water:acetic acid (90:9.5:0.5) in the extraction of phenolic compounds from the grape seeds. On the other hand, Baydar et al. (2004) analyzed TPC in grape pomace extracts of the Narince variety (white grape), and found that an ethyl acetate:methanol:water (60:30:10) mixture was more efficient than ethanol:water (95:5) in the extraction of phenolic compounds, with quantities reaching 45.44 and $29.55 \mathrm{mg} \mathrm{GAE} \mathrm{g}^{-1}$ extract, respectively. Özcan et al. (2004) determined the TPC in pomace extracts from the Emir (white grape) and Kalecik karasi (red grape) varieties, and got values that varied between 68.77 and 96.25 $\mathrm{mg} \mathrm{GAE} \mathrm{g}^{-1}$ extract, respectively. The authors used the same extraction method described by Jayaprakasha et al. (2003) for grape seeds, acetone:water:acetic acid (90:9.5:0.5). On the other hand, Anastasiadi et al. (2009) determined the TPC in grape pomace extracts from Voidomato and Mandilaria (red grape), and Asyrtiko and Aidani (white grape) varieties, all cultivated on the Greek islands, getting concentrations of 376.71, 207.79, 465.3, $107.12 \mathrm{mg} \mathrm{GAE} \mathrm{g}^{-1}$ extract, respectively. Sagdic et al. (2011) determined TPC from grape pomace extracts of two white grape varieties, Emir and Narince, and three red grape varieties, Gamay, Kalecik karasi, and Okuzgozu, all from Turkey, and got 75.5 - $281.4 \mathrm{mg} \mathrm{GAE} \mathrm{g}^{-1}$ extract. These results agree with our results in terms of the variables involved in the TPC yield, which are the kind and polarity of the solvents used in the extraction process, the extraction process itself, and the grape variety. Furthermore, our results of the TPC analysis of each of the fractions agreed with the identification of the compounds present in the grape pomace extracts obtained by the same methodology. According to HPLC studies, fractions obtained with hexane showed a low concentra- 
tion and diversity of the identified compounds, while the fraction extracted with ethyl acetate exhibited a greater concentration and diversity of phenolic compounds [15].

\subsection{Antibacterial Activity of Grape Pomace Extracts}

Respect to the antibacterial activity, our results indicate the existence of a broad spectrum activity present in the grape pomace of both varieties tested, in agreement with the results obtained by other authors [10] [21] [22] [24] [25]. Our results also indicate that grape pomace from Cabernet Sauvignon exhibits greater antibacterial activity than that from Syrah grapes. Oliveira et al. (2013) studied the antibacterial activity of grape pomace extracts of Syrah and Merlot. They determined that the extracts obtained from Syrah have lower antibacterial activity against all the bacteria tested, which is consistent with our findings.

Although the antibacterial activity of grape pomace extracts has been reported previously, this study shows the direct relation between the total content of phenolic compounds and antibacterial activity, concluding that the higher the amount of TPCs in the fractions, the greater the antibacterial activity [16] [22]. Oliveira et al. (2013) classified antibacterial plant extracts as "strong" if their MIC values are $\leq 500 \mu \mathrm{g} \cdot \mathrm{ml}^{-1}$.

The ethyl acetate fraction possesses a wide variety of phenolic compounds, identifying the following: gallic acid, vanillin, syringic acid, ellagic acid, myricetin, and quercetin, among others [15]. In the literature it has been reported that some of these phenolic acids and flavonoids possess antibacterial activity [14] [26] [27], which would explain the increased activity of the ethyl acetate obtained from the grape pomace varieties obtained in this work. Our results indicate that grape pomace is a rich source of antibacterial compounds that could be potentially added to animal food as bacterial growth control.

\section{Conclusion}

In this study it was determined that the grape pomace extracts obtained with chloroform and ethyl acetate from the Cabernet Sauvignon variety have a broad spectrum antibacterial activity against food transmitted pathogens. Our results suggest that the residue from Cabernet variety offers greater potential as a source of these compounds. In spite of the promising activity and the high amount of TPCs, studies on the identification of bioactive compounds and on the assessment of their mechanism of action are scarce. Furthermore, studies need to be directed toward the enhancement of antibacterial activity of grape pomace extracts and its possible synergistic effect with antibiotics used for the treatment of multiresistant bacterial strains.

\section{Acknowledgements}

This study was supported financially under FONDECYT Project 1130389 and by the Dirección de Investigación en Ciencia y Tecnología-USACH (DICYT-USACH). L. Sanhueza thanks the Comisión Nacional de Ciencia y Tecnología (CONICTY) for its support of her doctoral studies.

\section{References}

[1] Corrales, M., Fernandez, A., Vizoso, M.G., Butz, P., Franz, C. M., Schuele, E. and Tauscher, B. (2010) Characterization of Phenolic Content, in Vitro Biological Activity, and Pesticide Loads of Extracts from White Grape Skins from Organic and Conventional Cultivars. Food and Chemical Toxicology, 48, 3471-3476. http://dx.doi.org/10.1016/j.fct.2010.09.025

[2] Mandalari, G., Bisignano, C., D’Arrigo, M., Ginestra, G., Arena, A., Tomaino, A. and Wickham, M.S. (2010) Antimicrobial Potential of Polyphenols Extracted from Almond Skins. Letters in Applied Microbiology, 51, 83-89.

[3] Rockenbach, I.I., Rodrigues, E., Gonzaga, L.V., Caliari, V., Genovese, M. I., De Souza Schmidt Goncalves, A.E. and Fett, R. (2011) Phenolic Compounds Content and Antioxidant Activity in Pomace From Selected Red Grapes (Vitis vinifera L. and Vitis labrusca L.) Widely Produced in Brazil. Food Chemistry, 127, 174-179. http://dx.doi.org/10.1016/j.foodchem.2010.12.137

[4] Puupponen-Pimia, R., Nohynek, L., Hartmann-Schmidlin, S., Kahkonen, M., Heinonen, M., Maatta-Riihinen, K. and Oksman-Caldentey, K.M. (2005) Berry Phenolics Selectively Inhibit the Growth of Intestinal Pathogens. Journal of Applied Microbiology, 98, 991-1000. http://dx.doi.org/10.1111/j.1365-2672.2005.02547.x

[5] Mandalari, G., Bennett, R.N., Bisignano, G., Trombetta, D., Saija, A., Faulds, C.B., Gasson, M.J. and Narbad, A. (2007) Antimicrobial Activity of Flavonoids Extracted from Bergamot (Citrus bergamia Risso) Peel, a Byproduct of the Essential Oil Industry. Journal of Applied Microbiology, 103, 2056-2064. 
http://dx.doi.org/10.1111/j.1365-2672.2007.03456.X

[6] Hendra, R., Ahmad, S., Sukari, A., Shukor, M.Y. and Oskoueian, E. (2011) Flavonoid Analyses and Antimicrobial Activity of Various Parts of Phaleria macrocarpa (Scheff.) Boerl Fruit. International Journal of Molecular Sciences, 12, 3422-3431. http://dx.doi.org/10.3390/ijms12063422

[7] Lafka, T.I., Sinanoglou, V. and Lazos, E.S. (2007) On the Extraction and Antioxidant Activity of Phenolic Compounds from Winery Wastes. Food Chemistry, 104, 1206-1214. http://dx.doi.org/10.1016/j.foodchem.2007.01.068

[8] Yu, J. and Ahmedna, M. (2013) Functional Components of Grape Pomace: Their Composition, Biological Properties and Potential Applications. International Journal of Food Science \& Technology, 48, 221-237. http://dx.doi.org/10.1111/j.1365-2621.2012.03197.x

[9] Meyer, A.S., Jepsen, S.M. and Sörensen, N.S. (1998) Enzymatic Release of Antioxidants for Human Low-Density Lipoprotein from Grape Pomace. Journal Agricultural and Food Chemistry, 47, 2439-2446. http://dx.doi.org/10.1021/jf971012f

[10] Sagdic, O., Ozturk, I., Ozcan, G., Yetim, H., Ekici, L. and Yilmaz, M. (2011) RP-HPLC-DAD Analysis of Phenolic Compounds in Pomace Extracts from Five Grape Cultivars: Evaluation of Their Antioxidant, Antiradical and Antifungal Activities in Orange and Apple Juices. Food Chemistry, 126, 1749-1758. http://dx.doi.org/10.1016/j.foodchem.2010.12.075

[11] Oliveira, D.A., Salvador, A.A., Smania Jr., A., Smania, E.F., Maraschin, M. and Ferreira, S.R. (2013) Antimicrobial Activity and Composition Profile of Grape (Vitis vinifera) Pomace Extracts Obtained by Supercritical Fluids. Journal of Biotechnology, 164, 423-432. http://dx.doi.org/10.1016/j.jbiotec.2012.09.014

[12] Kammerer, D., Claus, A., Carle, R. and Schieber, A. (2004) Polyphenol Screening of Pomace from Red and White Grape Varieties (Vitis vinifera L.) by HPLC-DAD-MS/MS. Journal Agricultural and Food Chemistry, 52, 4360-4367. http://dx.doi.org/10.1021/jf049613b

[13] Corrales, M., Toepfl, S., Butz, P., Knorr, D. and Tauscher, B. (2008) Extraction of Anthocyanins from Grape ByProducts Assisted by Ultrasonics, High Hydrostatic Pressure or Pulsed Electric Fields: A Comparison. Innovative Food Science \& Emerging Technologies, 9, 85-91. http://dx.doi.org/10.1016/j.ifset.2007.06.002

[14] Xia, E.Q., Deng, G.F., Guo, Y.J. and Li, H.B. (2010) Biological Activities of Polyphenols from Grapes. International Journal of Molecular Sciences, 11, 622-646. http://dx.doi.org/10.3390/ijms11020622

[15] Mendoza, L., Yañez, K., Vivanco, M., Melo, R. and Cotoras, M. (2013) Characterization of Extracts from Winery by Products with Antifungal Activity against Botrytis cinerea. Industrial Crops and Products, 43, 360-364. http://dx.doi.org/10.1016/j.indcrop.2012.07.048

[16] Thimothe, J., Bonsi, I.A., Padilla-Zakour, O.I. and Koo, H. (2007) Chemical Characterization of Red Wine Grape (Vitis vinifera and Vitis Interspecific Hybrids) and Pomace Phenolic Extracts and Their Biological Activity against Streptococcus mutans. Journal of Agricultural Food Chemistry, 55, 10200-10207. http://dx.doi.org/10.1021/jf0722405

[17] Anastasiadi, M., Chorianopoulos, N.G., Nychas, G.J. and Haroutounian, S.A. (2009) Antilisterial Activities of Polyphenol-Rich Extracts of Grapes and Vinification Byproducts. Journal of Agricultural Food Chemistry, 57, 457-463. http://dx.doi.org/10.1021/jf8024979

[18] Brown, J. C., Huang, G., Haley-Zitlin, V. and Jiang, X. (2009) Antibacterial Effects of Grape Extracts on Helicobacter pylori. Applied and Environmental Microbiology, 75, 848-852. http://dx.doi.org/10.1128/AEM.01595-08

[19] Furiga, A., Lonvaud-Funel, A. and Badet, C. (2009) In Vitro Study of Antioxidant Capacity and Antibacterial Activity on Oral Anaerobes of a Grape Seed Extract. Food Chemistry, 113, 1037-1040. http://dx.doi.org/10.1016/j.foodchem.2008.08.059

[20] Kao, T.T., Tu, H.C., Chang, W.N., Chen, B.H., Shi, Y.Y., Chang, T.C. and Fu, T.F. (2010) Grape Seed Extract Inhibits the Growth and Pathogenicity of Staphylococcus aureus by Interfering with Dihydrofolate Reductase Activity and Folate-Mediated One-Carbon Metabolism. International Journal of Food Microbiology, 141, 17-27. http://dx.doi.org/10.1016/j.ijfoodmicro.2010.04.025

[21] Özkan, G., Sagdiç, O., Baydar, N.G. and Kurumahmutoglu, Z. (2004) Antibacterial Activities and Total Phenolic Contents of Grape Pomace Extracts. Journal of the Science of Food and Agriculture, 84, 1807-1811. http://dx.doi.org/10.1002/jsfa.1901

[22] Baydar, N.G., Özkan, G. and Sağdiç, O. (2004) Total Phenolic Contents and Antibacterial Activities of Grape (Vitis vinifera L.) Extracts. Food Control, 15, 335-339. http://dx.doi.org/10.1016/S0956-7135(03)00083-5

[23] Singleton, V.L. and Rossi, J.A. (1965) Colorimetry of Total Phenolics with Phosphomolybdic-Phosphotungstic Acid Reagents. American Journal of Enology and Viticulture, 16, 144-158.

[24] Jayaprakasha, G.K., Selvi, T. and Sakariah, K.K. (2003) Antibacterial and Antioxidant Activities of Grape (Vitis vinifera) Seeds Extracts. Food Research International, 36, 117-122. http://dx.doi.org/10.1016/S0963-9969(02)00116-3 
[25] Katalinić, V., Možina, S.S., Skroza, D., Generalić, I., Abramović, H., Miloš, M., Ljubenkov, I., Piskernik, S., Pezo, I., Terpinc, P. and Boban, M. (2010) Polyphenolic Profile, Antioxidant Properties and Antimicrobial Activity of Grape Skin Extracts of 14 Vitis vinifera Varieties Grown in Dalmatia (Croatia). Food Chemistry, 119, 715-723. http://dx.doi.org/10.1016/j.foodchem.2009.07.019

[26] Cowan, M.M. (1999) Plant Products as Antimicrobial Agents. Clinical Microbiology Reviews, 12, 564-582.

[27] Khadem, S. and Marles, R.J. (2010) Monocyclic Phenolic Acids; Hydroxy- and Polyhydroxybenzoic Acids: Occurrence and Recent Bioactivity Studies. Molecules, 15, 7985-8005. http://dx.doi.org/10.3390/molecules15117985 